\title{
O USO dE ANALOGIAS E METÁFORAS COMO RECURSOS DIDÁTICOS NO ENSINO DE FÍSICA
}

\author{
THE USE OF ANALOGIES AND METAPHORS AS DIDACTICAL \\ RESOURCE IN THE PHYSICSTEACHING
}

\author{
Fernanda Cátia Bozelli * \\ Roberto Nardi **
}

\begin{abstract}
Resumo
As relações entre linguagem e ensino de Ciências têm sido objeto de várias pesquisas nos últimos anos no Brasil, tendo se constituído numa promissora linha de pesquisa na área de Educação em Ciências. No caso específico da pesquisa em Ensino de Física, muitos dos pesquisadores têm mostrado interesse no levantamento de fenômenos físicos que podem ser expressamente comparados através do uso das analogias e metáforas. Entretanto, os estudos sobre as condições de produção das analogias e/ou metáforas pelo professor ou pelo aluno são ainda pouco estudados. Com esta pesquisa procura-se avançar nos estudos nessa linha, ao investigar: Como as analogias e metáforas são elaboradas e utilizadas pelo professor nas aulas de Física? Para responder a esta questão observou-se durante um semestre letivo as aulas de uma disciplina de Física Geral de um Curso de Licenciatura em Física de uma Universidade Pública do Estado de São Paulo, Brasil. Os resultados indicam que as analogias elaboradas e utilizadas pelo professor referiam-se ao universo sócio-relacional experimentado por ele, além de serem utilizadas de forma não programada, ou seja, espontaneamente, o que do ponto de vista dos alunos dificultava o entendimento do conceito.
\end{abstract}

Palavras-chave: Analogias, Metáforas, Ensino de Física.

* Grupo de Pesquisa em Ensino de Ciências - Programa de Pós-graduação em Educação para a Ciência. UNESP - Faculdade de Ciências - Câmpus de Bauru, São Paulo, Brasil. Apoio: FAPESP - Fundação de Amparo à Pesquisa do Estado de São Paulo. ferboz@fc.unesp.br

** Grupo de Pesquisa em Ensino de Ciências - Professor Adjunto - Depto. de Educação - Programa de Pós-ğraduação em Educação para a Ciência - UNESP - Faculdade de Ciências - Câmpus de Bauru, São Paulo, Brasil. Apoio: CNPq - Conselho Nacional de Pesquisa. nardi@fc.unesp.br 


\begin{abstract}
The relationship between language and science teaching has been object of research in the last few years in Brazil, constituting a promising line of research in Science Education. In the specific case of physics teaching research, many of the researchers have shown interest in raising physical phenomena which can be compared through the use of analogies and metaphors. However, the studies on the analogies and/or metaphors' conditions production by teachers or students are still few. We intended to advance in the studies on this subject, in order to answer questions like: How the analogies and metaphors are elaborated and used in Physics classes? In order to answer to this question we observed during one semester classes of a general physics course given to future High School teachers in a São Paulo State Public University, in Brazil. The results indicate that the analogies elaborated and used by the professor were related to his socio-relational universe, and also, the analogies were used in a not programmed or spontaneously way, which, from the students' point of view, made difficult the concepts understanding.
\end{abstract}

Key words: Analogies, Metaphors, Physics Teaching.

\section{INTRODUÇÃO}

Pode-se dizer que pesquisas na área de analogias e metáforas têm se constituído numa promissora linha de pesquisa na área de Educação em Ciências. Algumas das pesquisas realizadas destacam os estudos sobre a utilização das analogias e metáforas enquanto recurso didático, mediador entre os processos de ensino e de aprendizagem. Duit (1991), ao destacar o papel das analogias e metáforas na aprendizagem de Ciências, realiza extenso levantamento sobre os estudos realizados nos últimos 15 anos. Estudos como os realizados (Duit, 1991; Harrisson E Treagust, 1993; Thiele E Treagust, 1994; Dagher, 1995; Godoy, 2002) têm mostrado que as analogias e metáforas promovem o entendimento do que não é familiar para o que é comumente conhecido, mas ressaltam a importância em se estar atento para as limitações das mesmas.

No caso específico da pesquisa em Ensino de Física, muitos dos pesquisadores têm mostrado interesse no levantamento de fenômenos físicos que podem ser expressamente comparados através do uso das analogias e metáforas (Jorge, 1990; Herrmann E Schmid, 1985; Grant, 1996). Entretanto, os estudos sobre as condições de produção das analogias e/ ou metáforas pelo professor ou pelo aluno são ainda pouco estudados.

As considerações acima apresentadas levaram-nos a procurar avançar nos estudos nessa linha ao investigar: Como as analogias e metáforas são elaboradas e utilizadas pelo professor nas aulas de Física? 


\section{Analogias e metáforas como RECURSOS DIDÁTICOS}

As metáforas e as analogias são apontadas pelos investigadores como estratégias didáticas fundamentais no ensino e na aprendizagem de temas complexos pela possibilidade que elas oferecem de construir, ilustrar ou compreender um domínio científico (alvo) a partir de um domínio familiar (análogo) com base na exploração de atributos/relações comuns e não comuns de ambos os domínios.

Dos recursos didáticos existentes, a analogia é entendida como um mecanismo transferencial; tratando-se de uma das principais funções semióticas que permitem o processo de transposição didática (Galagovsky Y Adúriz-Bravo, 2001). Considera-se que, ao operar uma transposição didática sobre os saberes científicos para transformá-los em conteúdos escolares, pode se fabricar sobre os conteúdos uma nova representação -tanto analógica quanto metafórica- mediada por situações comuns ao conhecimento dos alunos:

\footnotetext{
A transposição didática (Chevallard, 1997) constitui a transformação do saber erudito em conhecimento a ensinar. É o processo pelo qual se escolarizam os conteúdos científicos. Para construir um modelo didático a partir do modelo científico, tem envolvido uma grande quantidade de operações de transposição no plano lógico (das formas) e no plano semântico (dos conteúdos). Algumas delas são: diminuir o grau
}

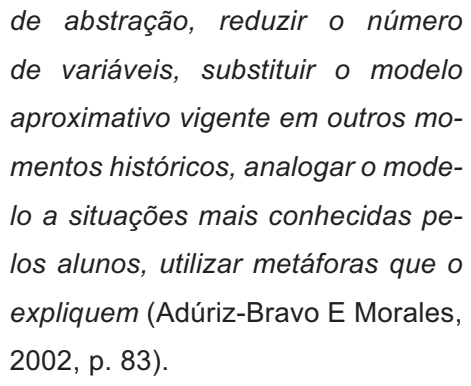

A importância da linguagem metafórica e analógica reside no fato de facilitar a transposição do conhecimento de um domínio conceitual não familiar para outro mais familiar. Tomar o conhecimento científico escolar como possível a partir de objetos do nosso entorno, modelados de forma a abstrair-se do supérfluo para concentrar-se nos detalhes essenciais, tem sido considerada uma forma frutífera nas relações entre ensino e aprendizagem de Ciências (Terrazzan, 1994). $\mathrm{O}$ uso da linguagem metafórica também tem sido considerado como uma das maneiras de fomentar um estilo menos rígido e mais expressivo na Educação em Ciências (Cachapuz, 1989).

As analogias podem ser recursos didáticos facilitadores da aprendizagem, pois utilizam conceitos e situações que possuem referentes na estrutura cognitiva dos alunos, onde estes referentes podem relacionar-se analogicamente com os conceitos científicos cuja aprendizagem se quer facilitar.

Segundo Duit (1991), os estudos sobre concepções alternativas ou representações prévias dos alunos em relação aos conceitos científicos evidenciam que eles freqüentemente tentam compreender os fenômenos através do emprego 
de analogias em áreas que são familiares a eles. Isto vem reforçar a idéia de que os conteúdos que devem ser explorados pelo professor no uso das analogias e metáforas são aqueles poucos "íntimos" dos alunos.

Analogias e metáforas não são as únicas formas de linguagem existentes, mas são provavelmente as mais utilizadas (Ferraz e Terrazzan, 2003). São usadas em diferentes perspectivas, mas é na situação educacional que freqüentemente aparecem.

Verificar a maneira como as analogias e metáforas têm sido abordadas em sala de aula foi objeto de estudo de diversos pesquisadores. Tierney (1988, apud Duit, 1991), observou quatro professores de estudos sociais durante suas aulas, ressaltando a maneira limitada com que as comparações são realizadas e a ausência de controle a respeito de como os alunos interpretam-nas, já que pressupõem que os estudantes estavam familiarizados com o domínio análogo e que poderiam usar metáforas, analogias e similares sem qualquer orientação.

Treagust et al. (1990, apud Duit, 1991), observando aulas de ciências de oito professores, perceberam que estes raramente usaram analogias no seu ensino (nas quarenta aulas observadas, somente em oito delas estas foram detectadas). Dagher (1995) observou 20 professores de ciências; destes, somente 11 usaram analogias em seu discurso. Nascimento (2000) observou professores e alunos do $10^{\circ}$ ano de escolaridade em Portugal, na disciplina de Ciências Físico-Químicas para averiguar se utilizavam tais recursos no seu discurso didático. $O$ estudo mostrou que professores e alunos as utilizaram em diferentes situações, mas não de maneira adequada. No Brasil, Ferraz e Terrazzan (2003) realizaram um estudo mais amplo em relação ao uso de analogias em sala de aula; observaram 152 aulas de seis professores de Biologia durante dois semestres. Nessas aulas, foram identificadas 108 ocorrências de analogias e metáforas.

Tomando-se por base os estudos acima, bem como as referências utilizadas nos mesmos, nota-se a importância em estar se averiguando como essas figuras de linguagem têm sido aplicadas no ensino de sala de aula como recursos didáticos disponíveis para o processo de construção de significações científicas.

\section{Analogias e metáForas NO ENSINO DE FÍSICA}

Um dos aspectos fundamentais da utilização das analogias e metáforas é a possibilidade que estas podem fornecer para estabelecer comparações entre o que é conhecido ou familiar, para o que não é familiar. Especificamente, no caso do Ensino de Física, as pesquisas têm mostrado, por exemplo, que as analogias e metáforas são ferramentas didáticas úteis na comparação de fenômenos semelhantes (Jorge, 1990, Otero, 1997, Herrmann E Schmid, 1985, Grant, 1996). Pacca e Utges (1999), particularmente, discutem em sua pesquisa a questão da transposição didática e a possibilidade da inserção das analogias para se tra- 
balhar um determinado conceito de física. Tais pesquisas têm constatado, por exemplo, que

O aprendizado da Física torna-se mais fácil e agradável se o estudo de um fenômeno novo for comparado a um fenômeno semelhante já conhecido. O estudo torna-se mais eficaz se a analogia é feita com um fenômeno encontrado na natureza ou de simples realização na sala de aula [...] A comparação entre fenômenos semelhantes contribui para a sedimentação dos conceitos semelhantes e facilita a introdução de conceitos novos (Jorge, 1990, p. 196).

Duit (1991) destaca a vantagem do emprego de analogias para facilitar a compreensão de "abstratos", assim como para provocar uma visualização dos mesmos. Esse poder de visualização das analogias é observado por Moreira (1997) quando este aponta que,

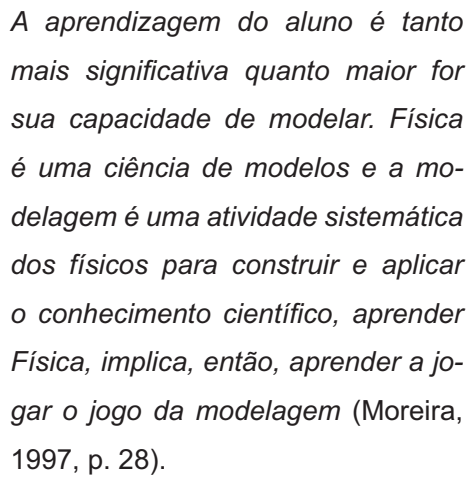

Alguns estudos identificam a utilização espontânea de analogias em salas de aula, em livros de texto e em artigos de divulgação científica, predominantemente como elemento enfático de relato de como explicar relações entre conceitos físicos através de uma linguagem comum. Dentre eles, pode-se destacar os estudos sobre eletricidade (Herrmann E Schmid, 1985; Grant, 1996; Jorge, 1990; Otero, 1997), óptica (Harrison E Treagust 1993) e ondas (Pacca E Utges, 1999).

Jorge (1990) destaca o importante papel desempenhado pelas analogias no ensino de física, uma vez que o professor pode utilizá-las em quase todas as áreas, tornando o seu ensino mais ameno e eficiente. Herrmann e Bruno Schmid (1985) acentuam a potencialidade da aplicação das analogias em contextos e temas diferentes, mas estruturalmente análogos.

\section{Aspectos METODOLógicos DA PESQUISA}

Considerando-se que o estudo proposto tem por base a observação e interpretação de como o professor de Física elabora e utiliza analogias e metáforas como recursos didáticos em suas aulas com a finalidade de construção dos conceitos científicos, a abordagem qualitativa foi escolhida por fornecer os elementos necessários ao processo desta pesquisa.

A metodologia empregada -a observação- empresta à pesquisa um caráter qualitativo, uma vez que a fonte direta dos dados é o próprio ambiente natural, sendo o investigador o instrumento principal da recolha de dados. Neste tipo de pesquisa, o pesquisador interessa-se mais pelo processo do que simplesmente pelos resultados (Bogdan E Biklen, 1991). Neste caso específico, realizou-se um "estudo 
de caso", que "[...] consiste na observação detalhada de um contexto, ou indivíduo, de uma única fonte de documentos ou de um acontecimento específico" (Merriam, 1988 apud Bogdan e Biklen, 1991). Estudos de caso como este, incidem sobre uma organização específica (a atuação do professor em sala de aula em um curso universitário), ao longo de um período determinado de tempo (um semestre), observando (com o auxílio de gravador e filmadora) e relatando (através desta comunicação) o seu desenvolvimento.

Assim, os dados foram recolhidos através do acompanhamento e registro das aulas da disciplina Física Geral II de um curso de licenciatura em Física, período noturno, de uma Universidade Pública do Estado de São Paulo, Brasil, durante um semestre letivo (2o/2003). Nesta disciplina estavam matriculados cerca de 40 licenciandos. $\mathrm{O}$ assunto abordado durante o semestre referia-se à Mecânica e os tópicos tratados foram, na seqüência, os seguintes: Impulso e Momento Linear, Colisões, Rotações, Torque e Momento Angular, Equilíbrio, Oscilações e Gravitação. Do período de setembro a novembro do ano de 2003, com o auxílio de gravações em áudio e em vídeo, foram observadas um total de 36 aulas. As gravações foram realizadas com o consentimento dos participantes, que autorizaram também a utilização dos dados obtidos na atual pesquisa, embora não se deu conhecimento do objeto de pesquisa, ou seja, docente e alunos não tiveram conhecimento prévio de que se estava observando o uso de analogias e metáforas durante as aulas. Foi garantida a preservação da identida- de de todos, em caso de publicação dos resultados da pesquisa. A seguir, todas as fitas foram ouvidas na ordem de gravação, transcrevendo-se todos os episódios ocorridos durante aquele semestre.

A observação das aulas permitiu, através de transcrições, que fossem mapeadas as analogias e metáforas utilizadas pelo professor e/ou pelos alunos e, também, algumas das interpretações por parte dos alunos (as partes destacadas nos episódios referem-se as metáforas e/ou analogias mapeadas).

Para melhor compreensão da elaboração e utilização feita pelo professor das analogias e/ou metáforas durante as aulas observadas, utilizamos para análise dois episódios de ensino selecionados das aulas observadas. Estes episódios são referentes a discussões envolvendo, respectivamente, os conceitos de "Rotação" e "Rolamento, Torque e Quantidade de Movimento Angular".

\section{Episódio 1}

Assunto Tratado: Movimento de Rotação

Alvo: Energia cinética de rotação

Análogo: Energia cinética de translação

Prof.:... Nós vamos estudar, vamos ter que estudar, um objeto em rotação. Ele também tem energia cinética associada a esse movimento de rotação e uma grandeza associada com essa energia cinética; uma grandeza importante do movimento de rotação que é o momento de inércia. Que faz o papel nas equações desse movimento angular pareci- 
do com o que a massa faz no movimento de translação. Esse é chamado momento inércia...

Neste primeiro episódio o tema abordado foi o de rotação. Neste caso, o professor faz uso da relação analógica entre conceitos científicos, mais especificamente, entre duas grandezas dos conceitos relacionados. O professor ressalta que o momento de inércia presente na equação da energia cinética de rotação

$\left(K=\frac{1}{2} I \omega^{2}\right)$ " [...] faz o papel [...] parecido com

o que a massa faz no movimento de translação $\left(K=\frac{1}{2} m v_{c m}^{2}\right)$ ".

Algumas investigações, como, por exemplo, as pesquisas de Hermann e Schmid (1985) e Jorge (1990) já alertavam para o fato de que, na área de Ensino de Física, o que ocorre freqüentemente é a utilização de analogias como ferramentas didáticas úteis na comparação de fenômenos (ou conceitos) semelhantes. Este fato veio ao encontro das nossas expectativas, no sentido de estar verificando se o professor na sua aula utiliza as analogias com este propósito. Isso fica evidente no trecho destacado.

De imediato, ele não estabelece as relações de semelhança entre os dois conceitos, supondo que os alunos já estejam familiarizados com o análogo. Este acontecimento foi observado na pesquisa realizada por Tierney (1988) quando observou professores de Estudos Sociais e ressaltou que eles não se preocupavam em estabelecer comparações e interpretações porque pressupunham que os alunos já estavam familiarizados com o análogo. O professor continua dizendo que os alunos iriam "[...] ver que é bastante simples e a matemática é bastante análoga ao que vocês já conhecem...?". A afirmação "vocês já conhecem" é muito relativa, pois até que ponto a matemática é realmente conhecida dos alunos? $\mathrm{O}$ fato de eles terem um contato anterior com a expressão em outro contexto (outro assunto), não significa que eles estejam familiarizados com o conceito alvo.

Em outro momento da aula, o professor utiliza novamente a relação entre dois conceitos científicos:

Assunto Tratado: Movimento de Rotação.

Alvo: Equação do Movimento com Aceleração Linear.

Análogo: Equação do Movimento com Aceleração Angular.

Prof.: [...] Um dos casos particulares importantes do movimento circular é quando eu tenho a aceleração angular uniforme, ou seja, ela varia até uma quantidade... tá? É o chamado movimento circular uniforme... O movimento circular uniforme, então, o $\alpha$ é constante... Se eu tenho as equações, pode ser que esse movimento... o movimento retilíneo uniforme, tá? Só que agora, vamos ter as grandezas angulares... Lembram que essas equações aqui são análogas a esta que está aqui? 
$\left[\left(\bar{\omega}=\bar{\omega}_{0}+\alpha t\right) \stackrel{\text { análog } a}{\longrightarrow}\left(v=v_{0}+a t\right)\right]$

O movimento circular uniforme é quando o ômega é constante... é uniformemente variado... ou acelerado...

Com relação a este trecho, o professor está explicando o conceito de movimento circular uniforme e, no momento em que faz referência às equações desse movimento, estabelece a relação analógica com as equações do movimento retilíneo uniforme: "[...] Lembram que essas equações aqui são análogas a esta que está aqui...?" As equações a que o professor se refere são $\left(w=w_{0}+\alpha t\right)$ e $\left(v=v_{0}\right.$ $+a t)$. Como domínio alvo, tem a equação do movimento com aceleração angular e, como domínio análogo, a equação do movimento com aceleração linear.

O uso de conceitos científicos como análogo fonte é entendido por alguns autores, como Duit (1991), como sendo arriscados, pois se o conceito utilizado como análogo tiver sido aprendido de forma errônea, o conceito alvo também o será. Além disso, este autor ressalta que áreas de conteúdo científico que são muito similares, quando utilizadas como análogas, podem ser vistas de maneiras distintas pelos alunos. Para Herrmann e Schmid (1985), essa relação pode possuir uma potencialidade quando aplicada em contextos e temas diferentes, mas estruturalmente análogos.

Jorge (1990) aponta que o aprendizado torna-se mais ameno e agradável se o estudo de um fenômeno novo for comparado a um fenômeno semelhante já conhecido do aluno. Ameno e agradável, no sentido de aproximar o aluno da explicação formal que está sendo utilizada pelo professor.

\section{Episódio 2}

Assunto Tratado: Rolamentos

Alvo: Energia Cinética de Rotação

Análogo: Energia Cinética de Translação

Prof.: [...] Se bem que a formulinha da energia cinética de rotação é ... [...] ... muito próxima da energia cinética de translação, tá certo? Onde o momento de inércia toma o lugar da massa... momento angular, desculpa, o momento angular toma o lugar da velocidade angular, desculpa velocidade linear ao quadrado. E essa grandeza, que nós chamamos de momento de inércia, que é uma espécie de..., mede a dificuldade de você colocar um objeto em rotação. Ela depende da massa do objeto, mas principalmente de como essa massa tá distribuída em relação ao eixo de rotação... Chamado, então, momento de inércia...

O segundo episódio abordou o tema "Rolamento, Torque e Quantidade de Movimento Angular", mais especificamente, rolamentos.

O professor, quando faz a relação analógica, espera que os alunos consigam comparar as grandezas alvo e análoga, mas a relação que ele estabelece não aborda as características estruturais de uma relação dessa natureza. O que acontece, então, é que os alunos ficam 
sem entender os domínios, alvo e análogo, e tentam, através de discussões com o professor, chegar a um consenso.

Prof.: Olha! Façam um paralelo se vocês pensarem neste tipo de coisa, tá? Façam um paralelo entre a massa e a velocidade linear de um objeto, tá?...massa e momento de inércia e velocidade angular, porque esse, um objeto qualquer que você tem, ele tem uma massa independente se ele tem velocidade ou não, tá? Mas se você quiser dar um momento pra esse objeto, você vai ter que multiplicar a massa pela velocidade. Se você quiser calcular a energia cinética, você tem que multiplicar a massa pela velocidade ao quadrado. Agora, o fato dele ter massa é uma propriedade intrínseca dele, é independente se ele tem velocidade ou não. Momento de inércia é a mesma coisa... momento de inércia é uma propriedade intrínseca do objeto ... mas, se você quiser fazer o giro do objeto em torno do próprio eixo... a dificuldade que você vai ter, vai depender do momento de inércia. Só que o fato dele ter velocidade angular ou não vai depender de quanta energia que você deu pra ele ou não, mas o momento de inércia continua lá, bonitinho, independente do cara ter velocidade angular ou não.

Aluno $\boldsymbol{A}_{1}$ : Mais esse cara aqui é zero? O momento de inércia?

Prof.: Só é zero se o objeto não tiver massa nem nada. O quê?
Aluno $\boldsymbol{A}_{1}$ : Se não tiver massa, né? Mas nos cálculos... velocidade zero daí eu não coloco, não vai dar o momento zero?

Prof.: Às vezes, pode dar zero, mas o momento de inércia não é zero, se você dizer que a velocidade é zero...

Aluno $A_{1}$ : Ah! Momento linear pode ser zero? Momento inercial é que não...

Prof.: O que você está falando? Pra um objeto, pra um movimento linear ou movimento angular?

Aluno $A_{1}$ : Movimento linear.

Prof.: Linear?

Aluno $A_{1}$ : Linear.

Prof.: Então você tem um objeto qualquer, tá parado lá, ele tem massa, não tem?

Aluno $A_{1}$ : Tem.

Prof.: Velocidade dele é zero. Ele não tem momento?...

Aluno $A_{1}$ : Isso.

Prof.: Certo? Se você empurrar o cara, e ele tiver velocidade, ele vai ter momento. O que é o momento? É o produto da massa pela velocidade... então, o fato dele ter massa é independente dele ter momento ou não. A máxima propriedade intrínseca dele, tá?

Aluno $A_{5}$ : Professor, o momento linear ou quantidade de movimento?

Prof.: Isso, isso... 
Aluno $\boldsymbol{A}_{5}$ Momento linear é ... o momento de inércia.

Prof.: Não, momento linear é uma coisa, o produto da massa vezes a velocidade, tá? 0 momento de inércia é uma coisa que parece com a massa, não parece com o momento linear. É o momento de inércia, tá? É... os nomes são meio confusos, tá? Tomem cuidado com a nomenclatura. Vocês vão ver que...

Aluno $A_{1}$ : Mas o momento de inércia se assemelha... à quantidade de movimento angular.

Prof.: Não, quantidade de movimento angular é coisa diferente: depende se aquele objeto, naquele momento de inércia, tem velocidade angular ou não. Se você deu velocidade pro cara, ele tem momento angular, se você não deu velocidade pra ele, ele não tem momento angular. Agora, ele sempre tem momentos de inércia. Porque é uma característica intrínseca do objeto, independente do movimento dele, tá? Então, o que vocês têm que ver é isso: o que depende do movimento, e que é propriedade intrínseca... Se vocês lembrarem da equaçãozinha que tava escrita aí no momento de inércia... Se vocês lembrarem da formulinha aí do momento de inércia... momento de inércia não depende da velocidade. Qualquer objeto que você imaginar... Imagina um eixo, tá? Imagina um eixo qualquer, um objeto com uma massa que tem seu momento de inércia...
Aluno $\mathrm{A}_{3}$ : Professor, esse objeto tem que fazer uma rotação?

Prof.: Independente do cara fazer uma rotação, tá? Parado ou... esse cara tem momento de inércia, com relação...

Aluno $A_{3}$ : Só tem que ter um eixo e uma massa.

Prof.: Ele tem um eixo e tem uma distribuição de massa, tá? Tendo isso, ele tem momento de inércia. É uma propriedade da distribuição de massa e propriedade geométrica da distribuição de massa, tá? Não interessa se ele já tá com velocidade ou se ele tá parado, mesma coisa que a massa.

Aluno $\mathbf{A}_{8}$ : Professor, mas definição de momento de inércia seria de.... rotação... momento linear... é...

Prof.: Ou se ele tá no repouso, a dificuldade pra você colocar ele... momento... Então, tanto faz; é a mesma quantidade. Se ele tá com uma determinada quantidade de movimento, tá certo? O efeito que você tem que fazer pra atingir a velocidade zero dá essa diferença, tá? Se o corpo tá em repouso, pra você colocar ele naquela velocidade, é o impulso que você precisa dar pra colocar o cara nessa velocidade. Tanto faz, se você tá parando, o corpo ou tá aumentando a velocidade dele.

Aluno $A_{4}$ : Então, a massa é pra você pôr em movimento linear?

Prof.: Isso. 
Aluno $A_{4}:$ A quantidade de movimento é uma dificuldade pra você parar esse corpo naquela velocidade? Por que ele já tem uma velocidade?

Prof.: É; depende do que você chama essa dificuldade, né? É o impulso.

\section{Aluno $A_{4}$ : Seu esforço pra levar a partícula ao repouso...}

Aluno $\mathbf{A}_{7}$ : $O$ corpo em repouso.

Prof.: Isso.

Aluno $A_{4}$ : Momento de inércia é a dificuldade que ele tem de se movimentar? De colocar em rotação?

Prof.: Isso.

Aluno $\boldsymbol{A}_{4}$ : Daí, nós podemos inferir que o momento angular vai ser a dificuldade de parar essa rotação.

Aluno $A_{7}$ : Não tem nada a ver momento angular com movimento de rotação?

Prof.: O momento... o problema é aquilo, você chama dessa medida... do momento de inércia. Acho que o problema dessas coisas que vocês estão falando é qual que é a medida que você tem no momento de inércia; quer dizer, momento de inércia não tem a ver com momento linear; momento de inércia é uma coisa mais parecida com a massa.

Aluno $A_{4}$ : Professor, esses conceitos são...

Prof.: São paralelos, são paralelos. Só que o momento de inércia, o paralelo dele é aquilo que você falou: é a massa, ou seja, em relação ao momento angular, a verdade formalmente embutida aí, tá? Momento angular é o produto do momento de inércia pela velocidade angular. Desculpa...momento angular é o produto do momento de inércia pela velocidade angular. Vamos fazer uma grandeza que a gente chama uma das grandezas importantes da Física, que a gente chama de momento angular é o produto do momento de inércia pela velocidade angular, tá? Essa é uma grandeza importante, porque se conserva da mesma maneira que o momento linear, tá? O paralelo que nós podemos traçar aqui é do momento de inércia, é do momento de inércia com a massa, não é do momento de inércia com o momento linear:

$$
\begin{aligned}
L & =I . w \\
P & =m \cdot v
\end{aligned}
$$

Aluno $\mathbf{A}_{4}$ : Não, professor, o que eu falei é o seguinte, a massa... ele oferece dificuldade.

Prof.: Eu não entendi, então...

\section{Aluno $A_{4}$ : Pra você colocar o corpo em movimento, a massa...}

Prof.: O movimento retilíneo...

Aluno $A_{4}$ : É; o movimento retilíneo. Aí, o momento linear é a dificuldade dele parar esse corpo que está em movimento, porque é no esforço que você faz parar ele.

Prof.: É, mais esse esforço aí não tá bem definido, né? Mas tudo bem! É o que a gente chama de impulso. 
Aluno $A_{4}$ : Isso. Você tem que fazer uma força pra fazer ele parar que vai ser...

Prof.: É a força vezes tempo; força vezes tempo... isso é o impulso.

Aluno: Mas é a mesma coisa, não é?

Aluno $A_{1}$ : Não é a mesma coisa; é diferente.

Prof.: Não, não... eu tô falando outra coisa.

Aluno $A_{1}$ : Ele tá andando e você parar, ou, se ele tá parado, você tentar fazer andar, é a mesma coisa que o momento linear, certo?

Prof.: Momento linear é isso aqui $(\mathbf{p}=\mathbf{m} . v)$, tá? Força é uma coisa do

tipo, taxa de variação desse

cara por tempo, ou seja, se você quiser calcular um delta $p$, isso é uma coisa do tipo (fórmula), tá?

Aluno $A_{4}$ : Então, pra você parar, pra você fazer o corpo entrar em repouso, você tem que aplicar o impulso que é uma força por determinado tempo pra fazer ele parar?

Prof.: Isso; aí ele tá parado. O momento que ele vai adquirir você tem que colocar uma força pra provocar um impulso quando chega lá.

Aluno $A_{4}$ : Agora, o momento de inércia é a dificuldade que tem de colocar ele em rotação, né?

Prof.: Isso.

Aluno $A_{4}$ : Aí que eu falei... eu inferi que o momento angular seria... é um tipo de uma dificuldade que eu tenho de colocar isso daí parado, de fazer o corpo parar de rodar, análogo ao momento linear.

Prof.: Isso! Isso!

Aluno $A_{4}$ : Então, tá certo?

Prof.: Beleza... É que a gente tem que ter alguns cuidados na linguagem, tá certo? De como a gente faz essas transferências pra não chegar em pontos equivocados. Presta bem atenção quando você tiver fazendo esses paralelos, tá? Uma coisa importante pra lembrar é isso daí: esse aqui, é o paralelo desse cara; esse, é o paralelo desse. Eles significam coisas diferentes, tá? Mas as coisas que acontecem com relação a eles são parecidas, as grandezas angulares com grandezas lineares... tá legal? Pra quem não acompanhou aí, tá, isso aqui chama $(L=I . W)$ momento angular ou quantidade de movimento 
e o que seria diferente entre os dois domínios.

É importante destacar que o professor, ao utilizar expressões como "se assemelha", "são paralelos", "são parecidas", "muito próxima", tenta fazer com que os alunos comparem os domínios relacionados e, dessa forma, cheguem aos aspectos principais em que está centrada a relação. A forma como o professor elabora a relação analógica fica no limite da superficialidade, o que colabora na dificuldade de entendimento do conceito. Para que essa superficialidade fosse superada, o professor precisaria entender que quanto maior o número de características comparadas entre o domínio da analogia e o domínio do alvo, maior será o poder explicativo da analogia.

Outro fator que colabora para o nãoentendimento de uma relação analógica diz respeito à linguagem utilizada, como na passagem: "Eles significam coisas diferentes, tá? Mas as coisas que acontecem com relação a eles são parecidas”.

O uso de expressões dessa natureza pode dificultar o entendimento dos alunos, pois, da forma como a relação é apresentada, torna-se difícil identificar as similaridades existentes.

Conforme mostram os episódios de ensino acima relatados, constata-se que o professor analisado faz uso das analogias e metáforas como recurso didático em sua prática pedagógica, mas a comparação fica no nível da superficialidade. Desse modo, é importante destacar o papel que os alunos precisam desempen- har ao estar interpretando as analogias e metáforas, no momento que o professor estabelece as relações entre o que é familiar e o que não é familiar.

\section{Considerações finaIS}

O fator determinante para a elaboração e utilização das analogias pelo professor nas aulas observadas diz respeito à dificuldade dos alunos em entender, compreender os conceitos explicados. Mas as analogias elaboradas pelo professor foram utilizadas de forma não programada, ou seja, espontaneamente. Por elas serem utilizadas dessa forma é ainda maior o compromisso de se estabelecer os limites de uma analogia ou de uma metáfora, já que nem todos os aspectos do domínio familiar são transferíveis para o domínio em estudo. Esse cuidado deve ser levado a sério, principalmente em situações que envolvam recursos como as analogias, pois a utilização das mesmas não pode ser realizada ao acaso; exige uma certa sistematização, programação.

Dessa forma, a elaboração de analogias requer um compromisso muito maior por parte do professor, mas também requer um forte compromisso por parte dos alunos, que devem trabalhar e relacionar o conceito com outras situações.

É importante, em um contexto de ensino-aprendizagem, que os alunos devem ter claro o estabelecimento de uma analogia, ou seja, não devem ficar somente com o entusiasmo da similaridade, senão realizar uma ação reflexiva sobre o significado da analogia e quais as limitações que ela apresenta. 
Entendemos que tal questão poderá trazer uma contribuição significativa para entender o processo de elaboração e/ou

\section{REFERÊNCIAS BIBLIOGRÁFICAS}

Adúriz-Bravo, A., y Morales, L. (2002). El concepto de modelo en la enseñanza de la Física - consideraciones epistemológicas, didácticas y retóricas. En Caderno Catarinense de Ensino de Física, v. 19, No. 1, pp. 79-92.

Bogdan, R. C., y Biklen, S. K. (1991). Pesquisa qualitativa em educação. Porto: Porto Editora, Portugal.

Cachapuz, A. F. (1989). Linguagem metafórica e o ensino das Ciências. En Revista Portuguesa de Educação, v. 2, No. 3, pp. 117-129.

Dagher, Z. (1995). Analysis of analogies used by science teachers. En Journal of Research in Science Teaching, v. 32, No.3, pp. 259-270.

Duit, R. (1991). On the role of analogies and metaphors in learning science. En Science Education, v.75, pp. 649-672.

Ferraz, D., y Terrazzan, E. (2003). Uso espontâneo de analogias por professores de biologia e o uso sistematizado de analogias: que relação? En Ciência \& Educação, v. 9, No. 2, pp. 213-228.

Godoy, L. A. (2002). Sobre la estructura de las analogías en Ciencias. En Interciencia, v. 27 , No. 8 , pp. $422-429$.

Harrison, A. G., y Treagust, D. F. (1993). Teaching with analogies: a case study in Grade-10 Optics. En Journal of Research in Science Teaching, v. 30, No. 10, pp. 1291-1307. interpretação do uso das analogias e/ou metáforas em situações de ensino e de aprendizagem.

Herrmann, F., y Schmid, B. (1985). Analogy between Mechanics and Electricity. En European Journal of Physics, v.6, pp. 16-21.

Galagovsky, L., y Adúriz-bravo, A. (2001). Modelos y Analogias em la Enseñanza de las Ciencias Naturales. El Concepto de Modelo Didáctico Analógico.En Enseñanza de las Ciencias. v. 19, No. 2, pp.231-242.

Grant, R. (1996). Basic Electricity - A novel analogy. En The Physics Teacher, v. 34, pp. 188-189.

Jorge, W. (1990). Analogia no ensino da Física. En Caderno Catarinense de Ensino de Física. v. 7, No. 3, pp.196-202.

Moreira, M. A. (1997). Modelos mentais. En Investigações em ensino de ciências, v. 3, pp. 1-39.

Nascimento, A. C. L. (2000). Linguagem e construção do conhecimento didático: metáforas e analogias no Ensino do tema equilíbrio químico - $10^{\circ}$ Ano de Escolaridade. In Encontro De Educação em Ciências, 2000, Universidade de Açores. Atas... Universidade de Açores.

Otero, M. R. (1997). ¿Cómo usar analogías en clases de Física? En Caderno Catarinense de Ensino de Física, v. 14, No. 2, pp. 170-178.

Pacca, J. L. A., y Utges, G. (1999). Modelos de onda no senso comum: as analogias como ferramentas de pensamento. In Encontro Nacional de Investigaçõesem Educação em Ciências, 2., Atas... Valinhos. 
Terrazzan, E. (1994). Perspectivas para a inserção da Física Moderna na escola média. 1994. Tese [Doutorado]. Faculdade de Educação, Universidade de São Paulo. São Paulo.

Thiele, R., y Treagust, D. (1994). An interpretative examination of High School Che- mistry teachers'analogical explanations. In Journal of Research in Science Teaching, v. 31, No. 3, pp. 227-242.

ARTíCULO RECIBIDO: 07-2004

Y APROBADO: 13-07-2005 